\title{
ON THE STABILITY OF MOBILE ROBOTS MOVEMENT WITH CABLE PROPULSION DEVICES
}

\author{
V. N. PLATONOV \\ Department of Theoretical Mechanics, Volgograd State Technical University, \\ Lenin av., 28, Volgograd, 400005, Russia \\ E-mail: platonov.vitaliy@yandex.ru \\ N. G. SHAPONOV \\ Department of Theoretical Mechanics, Volgograd State Technical University, \\ Lenin av., 28, Volgograd, 400005, Russia \\ Center for Technology Components of Robotics and Mechatronics, Innopolis University, \\ Universitetskaya str., 1, Innopolis, 420500, Russia \\ E-mail: sharonov@vstu.ru

\section{E. S. BRISKIN} \\ scientific adviser \\ Department of Theoretical Mechanics, Volgograd State Technical University, \\ Lenin av., 28, Volgograd, 400005, Russia \\ Center for Technology Components of Robotics and Mechatronics, Innopolis University, \\ Universitetskaya str., 1, Innopolis, 420500, Russia \\ E-mail:dtm@vstu.ru \\ dtm.vstu.ru
}

\begin{abstract}
The movement of the platform of the underwater mobile robot with an excessive number of propulsion devices, clinging to the reservoir's bottom, is considered. The task of determining the laws of the transition process, assessing its stability and quality indicators of control when establishing the specified relations between the efforts in the cables is studied.
\end{abstract}

\section{Introduction}

In the study of the mobile underwater robot motion which moves along the reservoir's bottom, one of the urgent tasks is to study the translational motion of such robot with walking movers $[1,2,3]$, in particular, the movement of an underwater platform-pontoon using anchor-cable propulsion devices. The principle of moving the underwater platform-pontoon with anchorcable propulsion devices $[4,5]$ is presented in Figure 1.

A feature of such robotic systems is an excess number of propulsion devices using for ensuring the required robot platform moving. This is explained by the need for reliable interaction of anchors with both hard-to-predict bottom topography and its physical and mechanical properties.

For the unambiguous implementation of the absolutely solid body motion at least six control effects are necessary, which in the considered task of the robotic platform movement corresponds to six anchor-cable propulsion devices interacting with the ground. In the absence of guaranteed interaction of at least one anchor with the ground, the movement of the robot becomes unpredictable. This leads the necessity to use an excessive number of propulsion devices. As a result, the number of control effects begins to exceed the number of independent 
generalized coordinates describing the mechanical system under consideration. In this case the dynamic uncertainty arises.

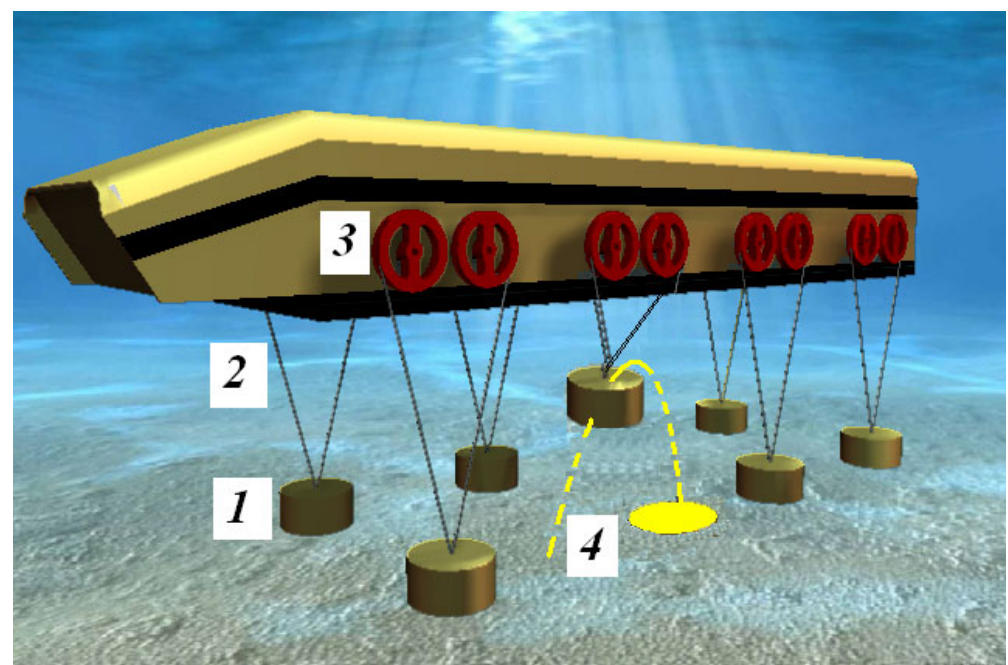

Figure 1. Principle of mobile robot operation with anchor-cable propulsion devices: 1 - anchor; 2 - cables; 3 - controlled flywheels; 4 - anchor transfer trajectory.

The task of distributing the dynamic load between several actuators according to one or another criterion is quite well known [6]. The simplest example is the automobile differential operation [7]. Cable robot control systems with multiple dives are also known [8]. The load distribution between several actuators is also implemented in control systems of an interconnected electric drive $[9,10]$.

\section{Formulation of the problem}

In [11] the equations of the load motion during the action of two control effects and solutions were obtained. That allows one to determine these effects (voltages supplied to the electric drives) for realizing the required force ratio in the propulsion device cables $\chi=T_{2} / T_{1}=$ const.

However, during the movement of the platform when the anchors are being rearranged, there is the necessity to change the ratio $\chi$ of forces in the propulsion device cables. Therefore, the force ratio $\chi_{j}=T_{j} / T_{1}$ is time-dependent $\chi_{j}=\chi_{j}(t)$. Here $T_{j}$ is the force in the $j$-th cable; $T_{1}$ is the force in the conditionally "basic" first cable. At those times when the first mover is being in the transference phase, any other should be taken as the "base" one. And in general, for mobile robots whose movers discretely interact with the supporting surface, the specified ratio $\chi_{j}(t)$ is piecewise continuous.

Therefore, the problem of determining the laws of the transition process and the problem of assessing its stability are arising. Also, the problem of determining indicators of control quality when establishing the given relations $\chi_{j}$ between the efforts in the cables $T_{j}$ and $T_{k}$ is arising.

In addition, using the DC-motors it is also possible to use stepper motors as drives. The difference is that the DC-motor is being controlled by changing the voltage supplied to the armature, and the stepper motor is being controlled by changing the switching frequency of its windings. In the case of using the DC-motors the controlled value is the motor shaft torque during the constant angular rotor's speed. In the case of using the stepper motor, the controlled value is the output shaft rotation angle. For more precise control of the moving load, the feature of stepper motors is preferable. 
Therefore, the task is to provide a required stable motion of the pontoon robot with certain defined relations between the forces $\chi_{j}$ developed by the drives that change discretely over time. The main problem is to reduce the transition time $\Delta t$, which affects the speed of the underwater platform-pontoon, as well as the smoothness of its movement. The task of the control system, in this case, is reduced to the search for control laws and propulsion devices parameters that will ensure the stability of the robot in general and the required qualitative and quantitative indicators of transients. In particular, the task of the control system is to provide the required duration $\Delta t$ sufficient to achieve the required platform's movement quality indicators as a whole.

\section{Solution method}

The method for solving this problem is based on the use of differential equations of the robot pontoon translational motion (Fig. 1):

$$
M \ddot{x}=-Q(\dot{x})+\sum_{j=1}^{2 N} T_{j}(x) A_{j}(x), j=1,2, \ldots 2 N,
$$

where $N$ is the number of movers; $M$ is the mass of the robot; $Q(\dot{x})$ - resistance to movement, depending on the robot pontoon's speed; $T_{j}(x)$ is the tension force of the $j$-th cable; $A_{j}(x)$ are known laws that depend on the design features of the propulsion drives. This design features link the forces in the $j$-th cable and the traction force developed by the $j$-th drive. In the simplest case, this is the cosine of the angle between the tensile force $T_{j}$ and the axis $O X$ (horizontal axis).

The first peculiarity of equation (1) is that even when moving is being with a constant speed the values $A_{j}(x), T_{j}(x)$ can depend on the robot pontoon's movement $x$. The second peculiarity of equation (1) is that the forces in the tensile cables can be of only one sign.

However, when the programmed motion is set, it is impossible to determine the forces $T_{j}$ from equation (1), since in this case one equation (1) contains $2 N$ unknown forces. To obtain an unambiguous solution, equation (1) should be supplemented by auxiliary $(2 N-1)$ equations that relate unknown forces in the cables $T_{j}$ to each other.

Such equations can take the form:

$$
\sum \mathrm{T}_{\mathrm{kj}}(\mathrm{x}) \mathrm{B}_{\mathrm{kj}}(\mathrm{x})=\mathrm{P}_{\mathrm{k}}(\mathrm{x}), \mathrm{k}=1,2, \ldots 2 \mathrm{~N}
$$

where $B_{k j}(x), P_{k}(x)$ area rectangular matrix and a column matrix respectively which in the general case must be determined from the extremum condition of the specified motion quality criterion $[6,11] ; k$ is the number of auxiliary equations. In the simplest case [11], for $N=1$, $k=1, P_{1}=0 ; B_{11}=-\eta$.

Equations (1) and (2) should be supplemented by equations relating the rotation angles of all propulsion devices $\psi_{j}$ with the robot pontoon's motion $x$ :

$$
\psi_{\mathrm{j}}=\psi_{\mathrm{j}}(x), j=1,2, \ldots 2 N
$$

Then the equations of the $j$-th DC-motor rotor rotational motion should be written:

$$
\mathrm{J}_{\mathrm{j}} \ddot{\varphi}_{\mathrm{j}}=\mathrm{k}_{\mathrm{j}} \mathrm{U}_{\mathrm{j}}-\mu_{\mathrm{j}} \dot{\varphi}_{\mathrm{j}}-\mathrm{T}_{\mathrm{j}} \mathrm{R}_{\mathrm{j}} / \mathrm{z}_{\mathrm{p}}, \varphi_{\mathrm{j}}=\mathrm{z}_{\mathrm{p}} \cdot \psi_{\mathrm{j}}(\mathrm{x}), \mathrm{j}=1,2, \ldots 2 \mathrm{~N}
$$

when $z_{p}$ is the DC-motor - flywheel gear ratio; $J_{j}$ - is the reduced moment of inertia

Equations (1) - (4) describe the steady-state process after the transferring of the next anchor to a new position and are true until the start of the transferring or installation of the next anchor to the bottom. These $8 N$ equations when the programmed motion $\dot{\mathrm{x}}=\mathrm{V}(\mathrm{t})$ is defined contain $8 N$ unknown variables: $\psi_{j}, \varphi_{j}, T_{j}, U_{j}$.

This process requires research on sustainability. For this, equations are compiled in variations of the studied process of movement, analyzed before the start of the transferring or installation of the next anchor of propulsion device on the bottom. 
If we take into account in (4) all the dependences $\varphi_{j}$ from (3), then the equation in variations when programmed motion is formed as:

$$
\dot{\mathrm{x}}=\mathrm{v}_{0}
$$

and it's corresponding:

$$
\varphi_{\mathrm{j}}=\varphi_{\mathrm{j}}(\mathrm{t})
$$

will look like:

$$
\left\{\begin{array}{c}
\mathrm{M} \delta \ddot{\mathrm{x}}+\frac{\partial \mathrm{Q}}{\partial \dot{\mathrm{x}}} \delta \dot{\mathrm{x}}-\sum_{\mathrm{i}=1}^{2 \mathrm{~N}} \frac{\mathrm{T}_{\mathrm{i}}}{\mathrm{z}_{\mathrm{p}}} \frac{\partial \mathrm{A}}{\partial \mathrm{x}} \delta \mathrm{x}-\sum_{\mathrm{i}=1}^{2 \mathrm{~N}} \frac{\mathrm{A}_{\mathrm{i}}}{\mathrm{z}_{\mathrm{p}}}(\mathrm{x}) \delta \mathrm{T}_{\mathrm{i}}=0 \\
\mathrm{~J}_{\mathrm{j}} \frac{\partial \varphi_{\mathrm{j}}}{\partial \mathrm{x}} \delta \ddot{\mathrm{x}}+\left[2 \mathrm{~J}_{\mathrm{j}} \frac{\partial^{2} \varphi_{\mathrm{j}}}{\partial \mathrm{x}^{2}} \mathrm{v}_{0}+\mu \frac{\partial \varphi_{\mathrm{j}}}{\partial \mathrm{x}}\right] \delta \dot{\mathrm{x}}+\left[\mathrm{J}_{\mathrm{j}} \frac{\partial^{3} \varphi_{\mathrm{j}}}{\partial \mathrm{x}^{3}} \mathrm{v}_{0}^{2}+\mu \frac{\partial^{2} \varphi_{\mathrm{j}}}{\partial \mathrm{x}^{2}}\right] \delta \mathrm{x}+\sum_{\mathrm{j}=1}^{2 \mathrm{~N}} \frac{\mathrm{R}_{\mathrm{j}}}{\mathrm{z}_{\mathrm{p}}} \delta \mathrm{T}_{\mathrm{j}}=0
\end{array}\right.
$$

A linearized system of equations between the beginning or completion of the transfer phase of the next anchor, characterized by the coordinate $x_{0}$, to the beginning or completion of the same stage of the next anchor, characterized by the coordinate $x_{f}$, can be represented in the form of $(2 N+1)$ linear differential equations in variations in the form:

$$
\mathrm{a}_{\mathrm{n}} \delta \ddot{\mathrm{x}}+\mathrm{b}_{\mathrm{n}} \delta \dot{\mathrm{x}}+\mathrm{c}_{\mathrm{n}} \delta \mathrm{x}+\sum_{\mathrm{j}=1}^{2 \mathrm{~N}} \mathrm{e}_{\mathrm{nj}} \delta \mathrm{T}_{\mathrm{j}}=0, \mathrm{n}=1 \ldots(2 \mathrm{~N}+1)
$$

where for $n=1$ :

$$
\begin{gathered}
\mathrm{a}_{1}=\mathrm{M} ; \\
\mathrm{b}_{1}=\frac{\partial \mathrm{Q}}{\partial \dot{\mathrm{x}}}=\xi ; \\
\mathrm{c}_{1}=-\frac{1}{\mathrm{x}_{\mathrm{f}}-\mathrm{x}_{0}} \int_{\mathrm{x}_{0}}^{\mathrm{x}_{\mathrm{j}}} \sum_{\mathrm{j}=1}^{2 \mathrm{~N}} \frac{\mathrm{T}_{\mathrm{j}}(\mathrm{x})}{\mathrm{z}_{\mathrm{p}}} \frac{\partial \mathrm{A}_{\mathrm{j}}}{\partial \mathrm{x}} \mathrm{dx} ; \\
\mathrm{e}_{1 \mathrm{j}}=\frac{1}{\mathrm{x}_{\mathrm{f}}-\mathrm{x}_{0}} \int_{\mathrm{x}_{0}}^{\mathrm{x}_{\mathrm{f}}} \frac{\mathrm{A}_{\mathrm{j}}(\mathrm{x})}{\mathrm{z}_{\mathrm{p}}} \mathrm{dx}
\end{gathered}
$$

and for $n>1$ :

$$
\begin{gathered}
\mathrm{a}_{\mathrm{n}}=\frac{1}{\mathrm{x}_{\mathrm{f}}-\mathrm{x}_{0}} \int_{\mathrm{x}_{0}}^{\mathrm{x}_{\mathrm{f}}} \mathrm{J}_{\mathrm{n}} \frac{\partial \varphi_{\mathrm{n}}}{\partial \mathrm{x}} \mathrm{dx} ; \\
\mathrm{b}_{\mathrm{n}}=\frac{1}{\mathrm{x}_{\mathrm{f}}-\mathrm{x}_{0}} \int_{\mathrm{x}_{0}}^{\mathrm{x}_{\mathrm{f}}}\left[2 \mathrm{~J}_{\mathrm{n}} \frac{\partial^{2} \varphi_{\mathrm{n}}}{\partial \mathrm{x}^{2}} \mathrm{v}_{0}+\mu \frac{\partial \varphi_{\mathrm{n}}}{\partial \mathrm{x}}\right] \mathrm{dx} \\
\mathrm{c}_{\mathrm{n}}=\frac{1}{\mathrm{x}_{\mathrm{f}}-\mathrm{x}_{0}} \int_{\mathrm{x}_{0}}^{\mathrm{x}_{\mathrm{f}}}\left[\mathrm{J}_{\mathrm{n}} \frac{\partial^{3} \varphi_{\mathrm{n}}}{\partial \mathrm{x}^{3}} \mathrm{v}_{0}^{2}+\mu \frac{\partial^{2} \varphi_{\mathrm{n}}}{\partial \mathrm{x}^{2}}\right] \mathrm{dx} \\
\mathrm{e}_{\mathrm{nj}}=\frac{\mathrm{R}_{\mathrm{j}}}{\mathrm{z}_{\mathrm{p}}}
\end{gathered}
$$

In expression (9) $\xi$ is the coefficient of viscous resistance to the movement of the robot pontoon in the liquid; $R_{j}$ is the radius of the $j$-th flywheel.

Thus, the $(2 N+1)$ equations in variations contain $(2 N+1)$ variables and, $j=1,2 \ldots 2 N$. The characteristic equation corresponding to differential equation (7) has the form: 


$$
\left|\begin{array}{ccccc}
\mathrm{a}_{1} \lambda^{2}+\mathrm{b}_{1} \lambda+\mathrm{c}_{1} & \mathrm{e}_{11} & \mathrm{e}_{12} & \ldots & \mathrm{e}_{12 \mathrm{~N}} \\
\mathrm{a}_{2} \lambda^{2}+\mathrm{b}_{2} \lambda+\mathrm{c}_{2} & \mathrm{R}_{1} & \mathrm{R}_{2} & \ldots & \mathrm{R}_{2 \mathrm{~N}} \\
\ldots & \ldots & \ldots & \ldots & \ldots \\
\mathrm{a}_{2 \mathrm{~N}+1} \lambda^{2}+\mathrm{b}_{2 \mathrm{~N}+1} \lambda+\mathrm{c}_{\mathrm{N}} & \mathrm{R}_{1} & \mathrm{R}_{2} & \ldots & \mathrm{R}_{2 \mathrm{~N}}
\end{array}\right|=0
$$

In order for the solution of differential equations to be stable, it is necessary that the real parts of all the roots of the characteristic equations be negative (the roots of the characteristic equation are located on the left side of the complex plane):

$$
\operatorname{Re}(\lambda)<0
$$

\section{The model task of studying the stability of the solid body translational motion when using two drives}

The problem of a rectilinear solid body motion with a constant speed, effecting by forces in the cables developed by two engines was considered in [11] and simulated the movement of a robot pontoon with two anchor-cable propulsion devices. In those article the dependences of the forces in cables $T_{1}(t), T_{2}(t)$ when ratio $T_{2} / T_{1}$ is defined are obtained. However, the stability of the obtained solution was not analyzed. The design scheme of the simulated motion is shown in Figure 2 .

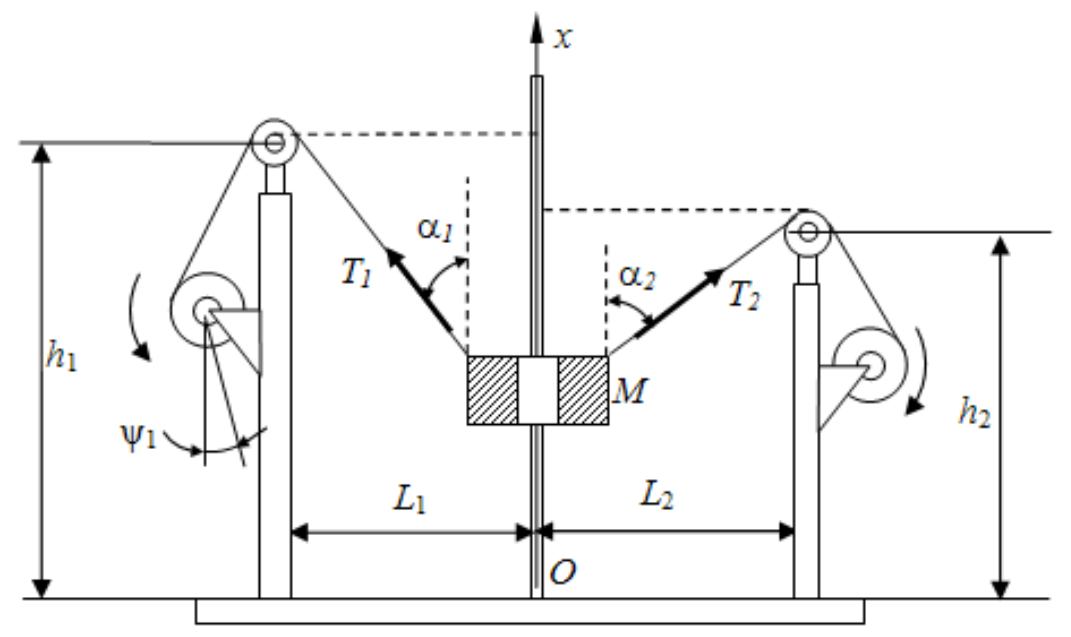

Figure 2. The settlement scheme providing studies of the motion stability.

To study the stability of the differential equations solution (7), it is necessary that the real parts of all the roots of the characteristic equation (11) be negative:

The characteristic equation for the case $R_{1}=R_{2}$ and the use of identical DC-motors has the form:

$$
\left(a_{2}-a_{3}\right) \lambda^{2}+\left(b_{2}-b_{3}\right) \lambda+\left(c_{2}-c_{3}\right)=0
$$

In accordance with the Routh-Hurwitz criterion [12] for stability it is required that the inequalities are being true:

$$
\begin{aligned}
& \mathrm{B}=\mathrm{b}_{2}-\mathrm{b}_{3}<0 \\
& \mathrm{C}=\mathrm{c}_{2}-\mathrm{c}_{3}<0
\end{aligned}
$$


For a model problem with given parameters (solid body's mass $M=0.5 \mathrm{~kg}$; flywheel mass and it's radii $m=0.24 \mathrm{~kg}, R=0.015 \mathrm{~m}$; DC-motor constant $\mu=0.014$; geometric dimensions $h_{2}=$ $0.3 \mathrm{~m}$ and $\left.L_{1}=L_{2}=0.19 \mathrm{~m}\right)$ and variable variables $\left(0<h_{1}<h_{2}, 0<V<V_{0}\left(V_{0}=0,08 \mathrm{~m} / \mathrm{s}\right)\right)$ in accordance with (10), obtained $A=a_{2}-a_{3}<0, B=b_{2}-b_{3}<0$.

Thus, the stability regions depend on the sign of coefficient $C$. The graph (Fig. 3) shows the dependence $C=C\left(h_{1}\right)$ for various values of speed $v$. Sustainable solutions correspond to zones in which $C<0$.

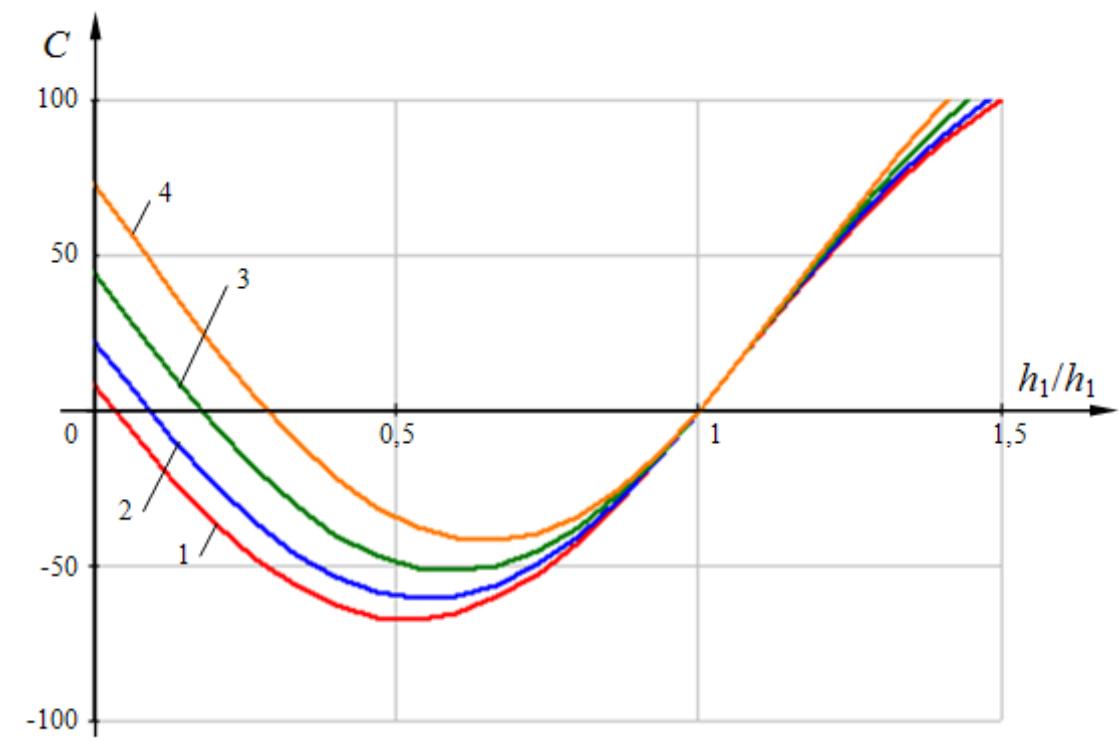

Figure 3.The dependence of the coefficient $\mathrm{C}$ on the ratio parameters $h_{1} / h_{2}$ for various values of speed $v$ : $1-v=0.3 v_{0} ; 2-v=0.5 v_{0} ; 3-v=0.7 v_{0} ; 4-v=0.9 v_{0}$

\section{Results}

1. An analysis of the dynamics of mobile robots motion with anchor-cable propulsion devices shows that when designing such robots and choosing modes of motion it is necessary to study the stability of motion. The need for such researching is also due to the requirement of minimizing the use of information-measuring systems due to the peculiarities of underwater movement.

2. The geometric parameters of the propulsion devices location, the mass-geometric and the energy characteristics of the drives can affect to the stability of movement.

3. For each type of such robots research should be conducted and areas of permissible parameters that ensure the stability of a particular robot movement should be determined.

\section{Acknowledgments}

The reported study was funded by RFBR, project number 19-38-90265.

\section{References}

1. Serov V A, Kovshov I V, Ustinov S A 2017 Tasks of technological robotic walking platforms in the development of underwater (ice) mineral deposits, Izvestiya YUFU. Tekhnicheskie nauki. 9 (194) pp 181-191.

2. Jin-Ho Kim, Tae-KyeongYeu, Suk-Min Yoon, Hyung-Woo Kim, Jong-Su Choi, CheonHong Min and Sup Hong 2013 Electric-Electronic System of Pilot Mining Robot, MineRo- 
II, Proceedings of the Tenth ISOPE Ocean Mining and Gas Hydrates Symposium Szczecin pp 269-273.

3. Chernyshev V.V. et al. 2016 Design and underwater tests of subsea walking hexapod MAK1,Proc. of the ASME 2016 35th International Conference on Ocean, Offshore and Arctic Engineering OMAE2016 / Ocean, Offshore and Arctic Engineering (OOAE) Division of The American Society of Mechanical Engineers (ASME), Pusan National University.7, 9 p.

4. Briskin, E., Sharonov, N., Serov, V. and Penshin, I. (2018). Motion control of underwater mobile robot with anchor-rope propulsion devices. Robotics and Technical Cybernetics, 2(19), pp.39-45..

5. Briskin E S, Penshin I S, Smirnaya L D and Sharonov N G 2017 Determination of forces in the engines of the anchor-cable type Izvestiya VolgGTU. Aktual'nye problem upravleniya, vychislitel'noj tekhniki i informatiki v tekhnicheskihsistemah.14 (209) pp 8790.

6. Briskin E S and Sharonov N G 2019 On motion Control of Mechanical Systems with an Excessive Number of Control Actions, Journal of Computer and Systems Sciences International. vol. 58, Issue 3 pp 374-381.

7. Zavatskiy A M and Kharitonov S A 2017 Development of algorithms for active torque distribution along the vehicle axes, Trudy NAMI. 2 (269) pp 37-47.

8. A.V. Maloletov, M.Y. Fadeev, A.S. Klimchik, Error Analysis in Solving the Inverse Problem of the Cable-driven Parallel Underactuated Robot Kinematics and Methods for their Elimination - IFAC-Papers OnLine, 52 (13), 1156-1161 (2019).

9. Eschin E K 2007 Upravlenie elektromagnitnym momentum parallel'no rabotayushchih asinhronnyh elektrodvigatelej ot odnogo invertora Vestnik Kuzbasskogo gosudarstvennogo tekhnicheskogo universiteta. 5 (63) pp 49-50.

10. Egorov E K 2010 Load distribution in multi-motor drives, VestnikKuzGTU.2 (78) pp 96-99.

11. Briskin E S and Platonov V N 2019 On Math Modeling of Solid Body's Motion Control with an Excess Number of Rope Propulsion Devices, Mechatronica, Avtomatizatsiya, Upravlenie. (7) pp 422-427.

12. Routh E J. A Treatise on the Stability of Motion.1877. 